\title{
Study on Structural, Morphological and Optical Characterization of Lithium Tetraborate Nanoparticles by High Energy Ball Milling
}

\author{
Neetu Rathore ${ }^{1,2, a}$, Asita Kulshreshtha ${ }^{1}$, Rajesh Kumar Shukla ${ }^{2}$ \\ ${ }^{1}$ Amity School of Applied Sciences, Amity University Uttar Pradesh, Lucknow Campus, Lucknow (India) \\ ${ }^{2}$ Department of Physics, University of Lucknow, Lucknow- Uttar Pradesh (India)
}

\begin{abstract}
Lithium tetraborate has attracted much attention as a potential radiation-proof material for an optical device. it is used as a tissue-equivalent material for radiation dosimetry. In the present investigation, we report the preparation of lithium tetraborate (LTB) nanoparticles by a solid -state method with high energy ball-milling along with different parameter. Different milling parameter was optimized to acquire essential particle sizes. The crystalline size obtained from XRD data is found within the range of $31-35 \mathrm{~nm}$. The morphological study was carried out using Scanning electron microscope. The structural properties of Lithium tetraborate was studied by Fourier transform infrared (FTIR) Spectroscopy.
\end{abstract}

Keywords:- Nanostructured Materials; High Energy Ball Milling Methods; XRD; FTIR; SEM.

\section{INTRODUCTION}

One of the reasons behind the interest of Lithium tetraborate $\left(\mathrm{Li}_{2} \mathrm{~B}_{4} \mathrm{O}_{7}, \quad \mathrm{LTB}\right)$ is that it resembles the biological tissues and can be used as a tissue-equivalent material. It is used for thermoluminescent radiation dosimeters for evaluation of absorbed dose in tissues ${ }^{1}$. LTB has an effective atomic number which is equivalent to soft biological tissue $\left(Z_{\mathrm{eff}}=7.42\right)^{2,3}$. LTB belongs to tetragonal crystal system and its polar point group symmetry is $4 \mathrm{~mm}$. Lithium tetraborate powder is most suitable for thermoluminescence dosimetry purpose and LTB has easy annealing procedures, high sensitivity, low fading and linear dose-response ${ }^{4}$.

The Lithium and Boron both have large neutron capturing capacity ${ }^{2}$. Lithium tetraborate shows piezoelectric and pyroelectric behaviour due to the peculiar crystallization system it has ${ }^{5}$. Transmission range of lithium tetraborate is $165-6000 \mathrm{~nm}^{6}$. LTB has several favourable properties, including linear and non-linear optical properties, luminescence, high radiation resistive, wide operation dose range. Another possible scope of lithium tetraborate material is to study the neutron capture characteristics of pure and doped LTB nanoparticles in the form of discs and as dispersed in a suitable matrix. It is reported in the literature that LTB has the potential for use in neutron dosimetry device ${ }^{6}$. LTB also exhibits interesting NLO properties ${ }^{2}$. Therefore, it is suggested that the NLO properties (for example, SHG efficiency) of nanoparticles in disc form and dispersed matrix form should be studied and compared with their single crystal counterpart.

In this paper, we report the preparation of LTB nanoparticles by high energy ball milling method. The milling parameter was optimized for obtaining the desired phase and particle size. Nanoparticles were characterized for structural, size, crystallinity and phase using XRD, FTIR, SEM techniques.

\section{CHARACTERIZATION}

The structural analysis of Lithium tetraborate nanoparticles was done by an X-Ray Diffractometer (Model- Ultima IV model from Rigaku, Japan) with $\mathrm{CuKa}$ radiation $(\lambda=0.15406 \mathrm{~nm})$. Fourier transmission infrared spectra of the nanoparticles were recorded in the range of 4000 to $400 \mathrm{~cm}^{-1}$ (Model-Nicolet TM 6700 Thermo scientific USA). The morphological studies were done by scanning electron microscope (Model-JSM 6490LV, Joel, Japan).

\section{EXPERIMENTAL METHOD}

A. Synthesis of Lithium tetraborate by high-temperature solid-state reaction

\section{> Material synthesis:}

For chemical preparation, Stoichiometric ratio of $\mathrm{Li}_{2} \mathrm{~B}_{4} \mathrm{O}_{7}$, i.e. $\mathrm{Li}_{2} \mathrm{CO}_{3}: 2 \mathrm{~B}_{2} \mathrm{O}_{3}$ in $1: 2$ ratio are taken. The amount of reactant $\mathrm{Li}_{2} \mathrm{CO}_{3}$ and $\mathrm{B}_{2} \mathrm{O}_{3}$ required for the desired amount of $\mathrm{Li}_{2} \mathrm{~B}_{2} \mathrm{O}_{7}$ was taken considering the platinum crucible size, which is to be used. Therefore to compute the mass of reactants required for this amount of charge.

$$
\mathrm{Li}_{2} \mathrm{CO}_{3}+2 \mathrm{~B}_{2} \mathrm{O}_{3}=\mathrm{Li}_{2} \mathrm{~B}_{4} \mathrm{O}_{7}+\mathrm{CO}_{2}
$$

The material was taken for $190 \mathrm{gm} \mathrm{Li}_{2} \mathrm{~B}_{4} \mathrm{O}_{7}$. The materials were properly mixed and heated at $350{ }^{\circ} \mathrm{C}$ for 4 hrs then again mixing in an agate mortar. In the second step, the process was repeated and the material was heated at $750^{\circ} \mathrm{C}$ for $7 \mathrm{hrs}$ then again mixing to get proper material for ball milling. This reacted powder was then kept inside the bowl for ball milling. the milling was done for different rpm and different time. 


\section{B. Preparation of Lithium Tetraborate Nano Powder By} High Energy Ball Milling:

The nanoparticles of LTB were prepared by a wet grinding process in a planetary ball milling. The containers are fixed on a surface which rotates until the centrifugal acceleration reaches 30 to 50 times the acceleration due to gravity. Heavy milling balls increases the impact energy on collision. The material, prepared by the solid-state reaction is divided into 2 parts to put into containers. For wet grinding, ethyl alcohol is used as a grinding medium. 1:1 ratio ball to powder mass ratio (BPMR) is used, so $100 \mathrm{gm}$ of lithium tetraborate and $100 \mathrm{gm}$ of zirconia balls $(2 \mathrm{~mm})$ was put into the containers. Milling was done for different milling time with different milling rotation per minute. Several runs were performed to get nanosize particle. As the speed of the machine is very high during rotation, the temperature of the bowl may increase abruptly. To avoid this, pause time is required in between two rotation cycle. Pause time was set as 5 min for every cycle.

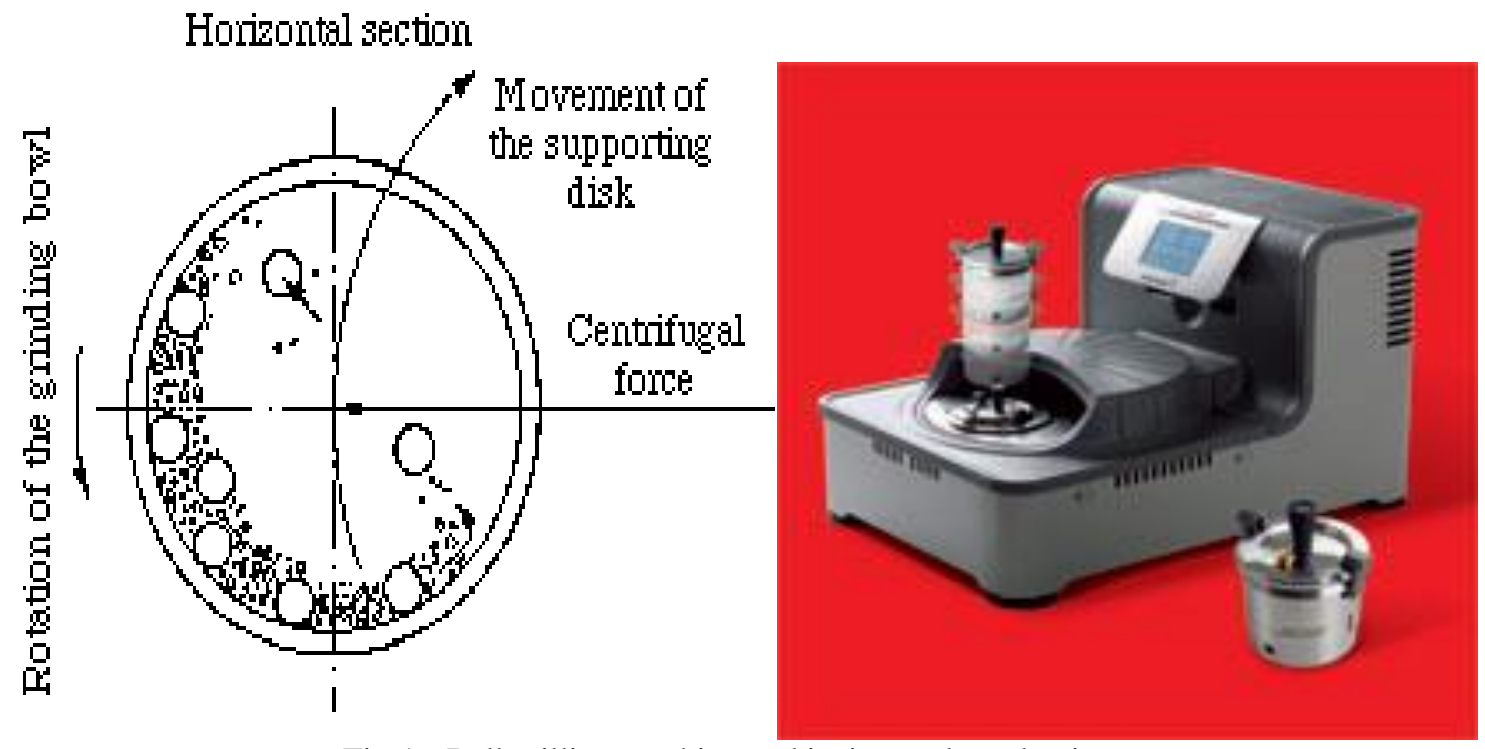

Fig 1:- Ball milling machine and its internal mechanism.

C. Parameters on which ball milling depends:

$>$ Ball to powder mass ratio (BPMR)

$>$ Size of ball

$>$ Material of balls

$>$ Properties of parent Material

$>$ Milling time

Milling atmosphere

$>$ Speed of rotation (RPM)

$>$ Milling medium

\section{RESULT AND DISCUSSION}

\section{A. XRD analysis}

X-ray Diffraction is for obtaining information about the structure, phase analysis and particles size. Phase identification of grown pure LTB nanopowder was carried out by X-ray diffraction (XRD) measurement. At room temperature, structural parameter for LTB are as follows, lattice constants $\mathrm{a}=\mathrm{b}=9.477 \AA, \mathrm{c}=10.286 \AA$ and space group I41cd [4]. The XRD patterns were obtained with $2 \theta$ in the range of 20 to 70 by step scanning, using $2 \theta$ increment of 0.02 degree. All peaks matched well from JCPDS data (no. 20-0631) which belongs to 21.6 (112), 22.6 (211), 25.5 (202), 33.6 (213), 34.6 (312), 37.9 (400), 39.8 (204), 41.9 (402), 42.6 (420), 43.3 (323), 44.2 (332), 47.6 (413), 48.8 (431), 52.3 (512), 55.3 (116), 56.3 (424), 61.4 (602), 66.92 (444). The crystalline size (D) can be calculated using Debye-Scherrer formula ${ }^{6}$.

$$
\text { Crystalline size }(D)=0.9 \lambda / \beta \operatorname{Cos} \theta
$$

Where $\lambda$ is the wavelength of X-ray $(0.15406 \mathrm{~nm}), \beta$ is the Full width at half maximum of the peaks; $\theta$ is the Bragg's angle of the X-ray diffraction. The crystalline size obtained for XRD at a different temperature within the range of 31-35 $\mathrm{nm}$.

The X-ray patterns of pure LTB samples ball milled for different milling time for 7 hours and 21 hours are shown in Fig. 2 and Fig. 3 respectively. 

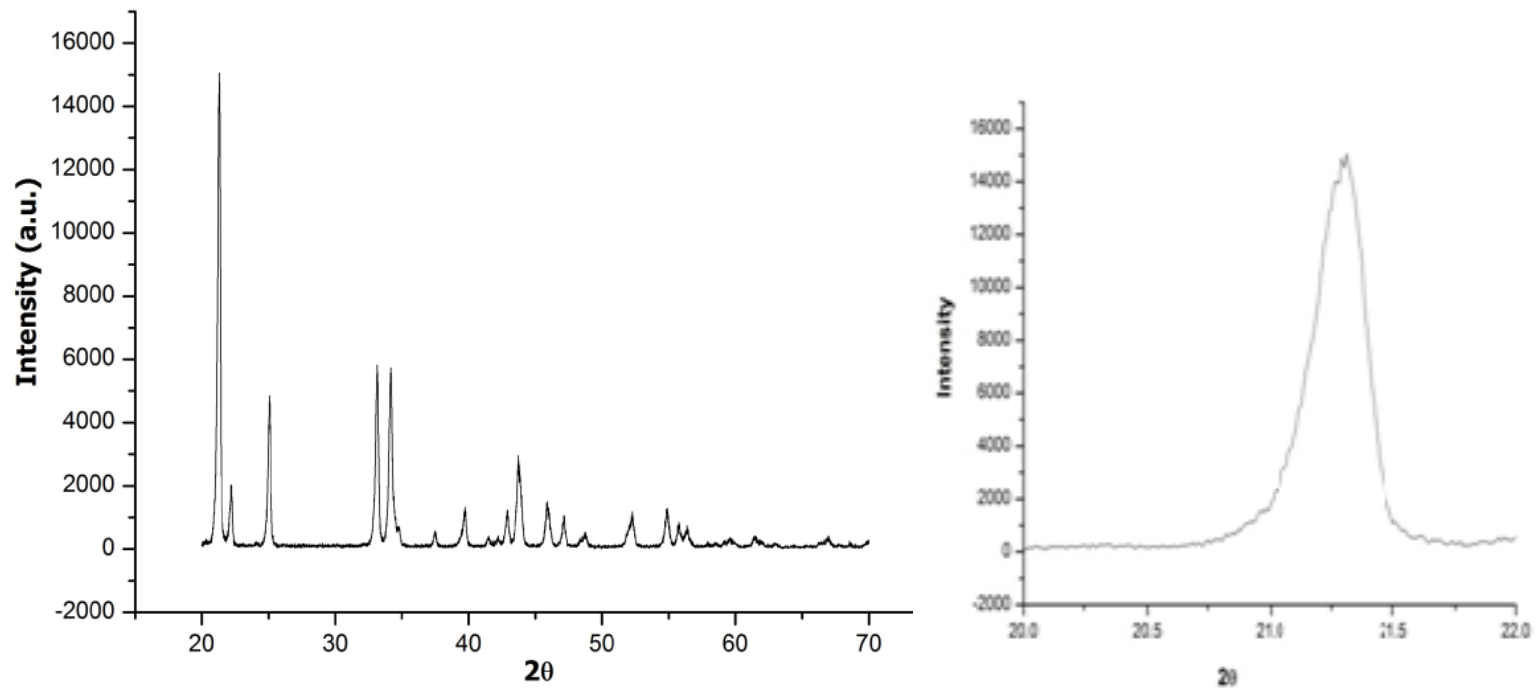

Fig 2:- XRD pattern of pure LTB nanopowder after 7 hours ball mill time.
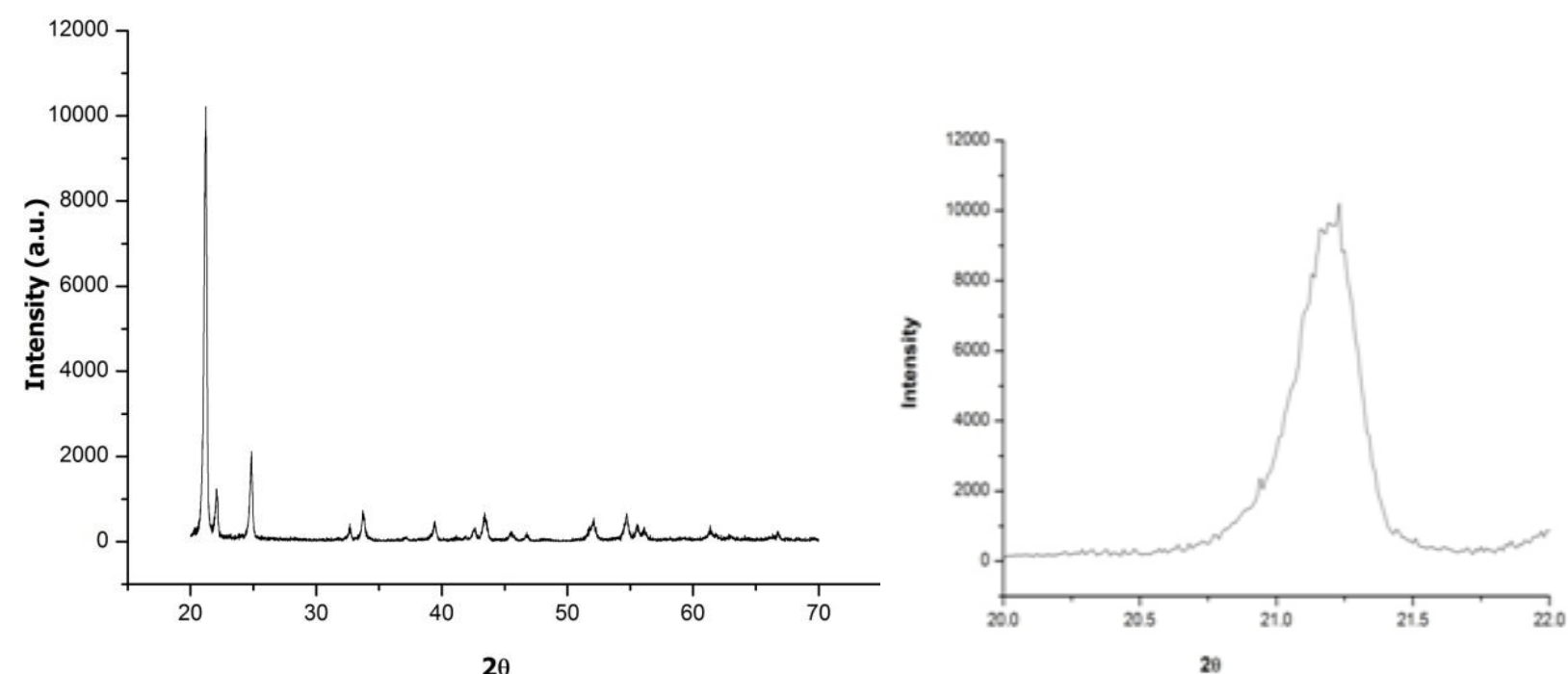

Fig 3:- XRD pattern of LTB nanopowder after 21 hours of ball mill time.

\begin{tabular}{|c|c|c|c|}
\hline $\begin{array}{c}\text { Milling speed } \\
\text { ( in rpm) }\end{array}$ & $\begin{array}{c}\text { Milling time } \\
\text { (in hour) }\end{array}$ & $\begin{array}{c}\text { FWHM } \\
\text { (in degree) }\end{array}$ & $\begin{array}{c}\text { Crystallite size } \\
\text { (in nm) }\end{array}$ \\
\hline 300 & 7 & $\mathbf{0 . 2 2 8 2}$ & 35 \\
\hline 300 & 21 & 0.256 & 31 \\
\hline
\end{tabular}

Table 1:- Represents variation of particle size of pure LTB with an increase of milling time.

From the above graphs and table 1, it is concluded that as the milling time is increasing the FWHM is increasing, resulting in a decrease of crystallite size. It is a comparative study of size measurement of particle. It does not provide an accurate measurement of particle size. Because the broadening which we have measured is not only due to the size effect of particle it also includes the instrumental broadening and broadening due to strain inside the particle.

\section{B. FTIR analysis}

Fig. 4 shows the FTIR spectrum of LTB nanoparticles. FTIR provides specific information about network structures and functional groups of nanoparticles. 




Fig 4:- FTIR spectrums of Lithium tetraborate nanoparticles.

Bands reveals the characteristic peak at $3435.9 \mathrm{~cm}^{-1}, 1978.9 \mathrm{~cm}^{-1}, 1140.6 \mathrm{~cm}^{-1}, 981.4 \mathrm{~cm}^{-1}, 901.6 \mathrm{~cm}^{-1}, 776.7 \mathrm{~cm}^{-1}, 682.5 \mathrm{~cm}^{-}$ ${ }^{1}, 657.5 \mathrm{~cm}^{-1}, 547.5 \mathrm{~cm}^{-1}, 510.7 \mathrm{~cm}^{-1}$. The three spectral range of a functional group of borates normally corresponds to the vibration modes. The first section $1200-1750 \mathrm{~cm}^{-1}$ is the first region which belongs to asymmetric stretching and bending vibration of the B$\mathrm{O}$ bond of trigonal $\mathrm{BO}_{3}$ unit ${ }^{7}$. The next second region $800-1200 \mathrm{~cm}^{-1}$ is allied with $\mathrm{B}-\mathrm{O}$ bond stretching of tetrahedral $\mathrm{BO}_{4}$ units. The last third region between $600-800 \mathrm{~cm}^{-1}$ band correlated from bending vibration of B-O-B linkages in the boron-oxygen network ${ }^{2,8}$. The absorption band $3437.9 \mathrm{~cm}^{-1}$ signify the $\mathrm{O}-\mathrm{H}$ stretching vibration ${ }^{8}$. Li containing compound show that peaks related to $300-510 \mathrm{~cm}^{-1}$ are an attribute of $\mathrm{Li}$ coordinated by four $\mathrm{O}$ nearby neighbours. The peak at $420 \mathrm{~cm}^{-1}$ for the LiBO ${ }_{2}$ and $\mathrm{Li}_{2} \mathrm{~B}_{4} \mathrm{O}_{7}$ crystals have earlier been assigned to $\mathrm{Li}$.

\section{SEM Analysis}

The electrons interact with atoms in the sample which produces various signals that can be detected. This gives important information regarding growth mechanism size and shape of the sample.

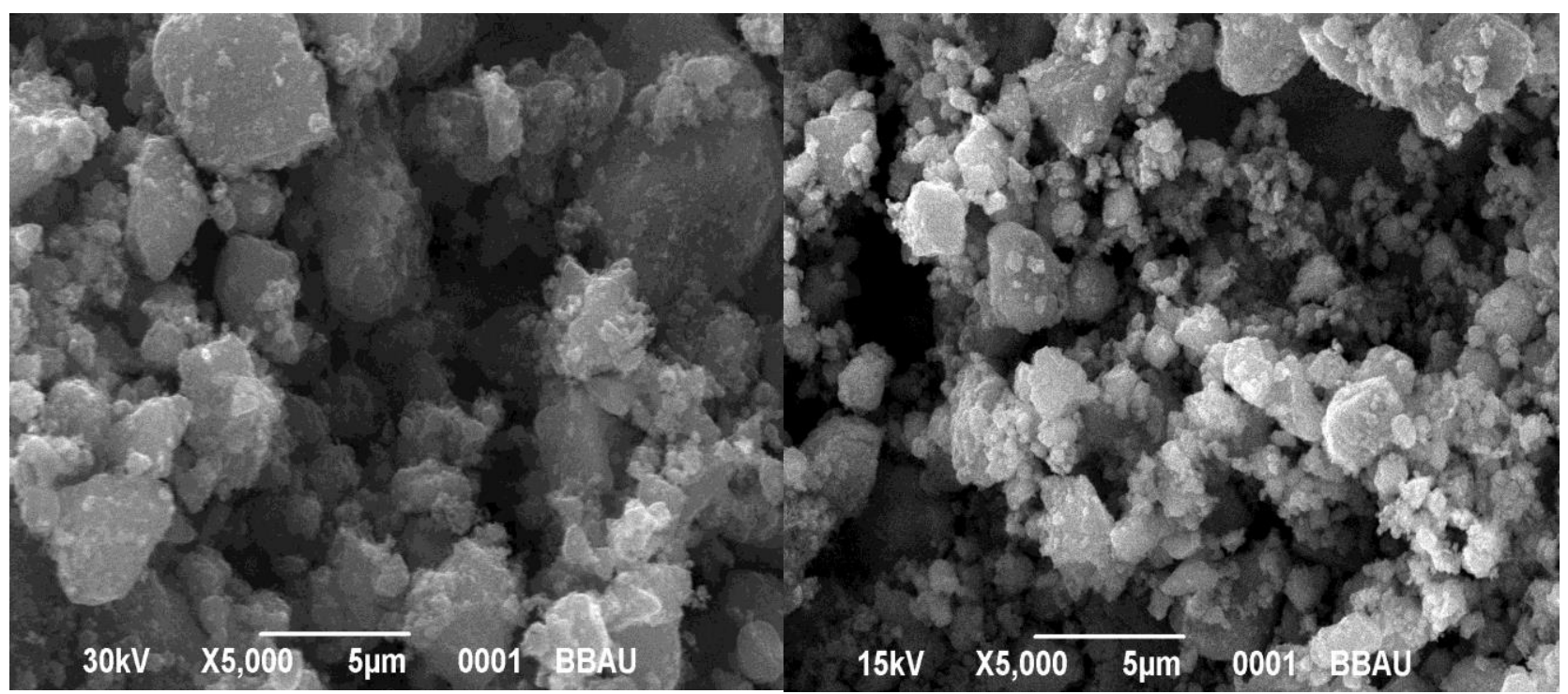

(a)

(b)

Fig 5:- SEM images for ball-milled nanoparticles at 7 hours (a) and (b)21hours

The morphology and textural properties of the nanoparticles were characterized by scanning electron microscopy. Figure 5(a) and 5(b) show the SEM micrograph taken for lithium tetraborate nanoparticles ball milled at 7 hours and 21 hours respectively. Surface morphology explored through SEM reveal that with increase in milling time from 7 hours to 21 hours, size of the particles and porosity decreases. The SEM study shows that all samples are highly crystalline and particles are uniformly distributed. 


\section{CONCLUSIONS}

The formation of pure $\mathrm{Li}_{2} \mathrm{~B}_{4} \mathrm{O}_{7}$ nanoparticles is confirmed by powder XRD. High energy ball milling technique used for preparation of LTB nanoparticles depends on different parameters like the ball to powder mass ratio, milling time, rpm, ball size etc.,. These parameters were optimized to get almost uniform particle size. Increasing the milling time decreases the particle size. Also it has been perceived that wet grinding is favoured to obtain smaller particle size. The Lithium tetraborate nanoparticles were investigated for their particle size, phase and structure. SEM study was used to observe morphology and size of particles which is in the range of 51 to $300 \mathrm{~nm}$. FTIR used for spectroscopic investigation confirms the presence of various normal modes of vibration for the material.

\section{REFERENCES}

[1]. B. Tiwari, N.S. Rawat, D.G. Desai, S.G. Singh, M. Tyagi, P. Ratna, S.C. Gadkari, and M.S. Kulkarni, "Thermoluminescence studies on Cu-doped Li 2 B 4 O 7 single crystals," J. Lumin., 130 [11] 2076-2083 (2010).

[2]. E. Pekpak, A. Y1lmaz, and G. Özbayo, "The effect of synthesis and doping procedures on the thermoluminescent response of lithium tetraborate," 509 2466-2472 (2011).

[3]. N. Khalilzadeh, E. Bin Saion, H. Mirabolghasemi, A.H. Bin Shaari, M. Bin Hashim, M.B.H. Ahmad, N.M. Ali, and A. Dehzangi, "Single step thermal treatment synthesis and characterization of lithium tetraborate nanophosphor," J. Mater. Res. Technol., 5 [1] 37-44 (2016).

[4]. D. Use, E. Pekpak, A. Y, and G. Özbayoglu, "An Overview on Preparation and TL Characterization of Lithium Borates for An Overview on Preparation and TL Characterization of Lithium Borates for Dosimetric Use," [May] (2010).

[5]. S. Dhanuskodi, R. Mohandoss, and G. Vinitha, "Preparation and optical properties of cobalt doped lithium tetraborate nanoparticles," Opt. Mater. (Amst)., 36 [9] 1598-1603 (2014).

[6]. S. Kar, S. Verma, and K.S. Bartwal, "Preparation of Mn doped Li 2 B 4 O 7 nanoparticles by glass quenching," J. Alloys Compd., 495 [1] 288-291 (2010).

[7]. L.M. Frantz, R.L. Mills, R.G. Newton, A.M. Sessler, T. Film, S.R. Meher, L. Balakrishnan, H.J. Lin, et al., "Preparation of Titanium Dioxide (TiO2) Via the SolGel Process.," Surf. Coatings Technol., 1 [1] 2-5 (2013).

[8]. A. Kumaresh, R. Arun Kumar, N. Ravikumar, U. Madhusoodanan, B.S. Panigrahi, K. Marimuthu, and M. Anuradha, "Structural and photoluminescence studies on europium-doped lithium tetraborate (Eu:Li2B4O7) single crystal grown by microtube Czochralski ( $\mu \mathrm{T}-\mathrm{Cz}$ ) technique," Chinese Phys. B, 25 [5] 2-6 (2016). 